\title{
Microplastics pollution of seafoods and processed seafood products distributed in Incheon area
}

\author{
Ji Sun Kim*, Kyoung Hwa Whang, Seung Eun Jang, Sung Min Song, \\ Yun Sun Im, Young Sun Han, Myung Je Heo \\ Division of Food Analysis on the Food and Drug Administration, Incheon Metropolitan City \\ Institute of Public Health and Environment, Incheon 22320, Korea
}

\section{인천지역 유통 수산물 및 수산물가공품 중 미세플라스틱 오염도 조사$$
\text { 김지선* · 황경화 · 장승은 · 송성민 · 임윤선 · 한영선 · 허명제 }
$$$$
\text { 인천광역시 보건환경연구원 식약연구부 식품분석과 }
$$

\begin{abstract}
This study was intended to obtain the basic data for a wide range of microplastics (MPs) contamination studies. The contamination of MPs in seafood and processed seafood products distributed in Incheon area was quantified. For this, 51 seafoods and 50 processed seafood products in Incheon were collected randomly from January 2019 to October 2019, and the abundance, size, and type of MPs in the samples were identified by FT-IR spectroscopy. The average MPs content was 1.06 $\pm 3.38 \mathrm{MPs} / \mathrm{g}$ and $0.89 \pm 1.29 \mathrm{MPs} / \mathrm{g}$ in seafoods and processed seafood products, respectively. In both samples, MPs of 100-500 $\mu \mathrm{m}$ accounted for the majority of the particles, with the most common MPs as polyethylene (PE) and polypropylene (PP). However, the level of contamination of MPs in each of the samples was significantly different, even for the same species. For more accurate analysis of MPs contamination in seafoods and processed seafood products, specific information such as habitat, environment, market supply, regional source, and production process might be required. In addition, extensive and continuous accumulation of data is necessary for them to be used as the basic data with a standardized method for analyzing MPs.
\end{abstract}

Key words : microplastics, FT-IR, seafood, processed seafood products, plastic pollution

서 론

1950년대 이후 플라스틱 생산량은 거의 모든 다른 재료의 생산량을 능가하고 있으며, 2012년에는 2억 8천만 톤, 현재 추세라면 2050년까지 330억 톤에 이를 것으로 추정되고 있 다(Birol, 2018). 이러한 플라스틱은 해양쓰레기의 $80 \%$ 를 차 지하고 있으며, 대부분은 한 번만 사용하면 버려지도록 설계 되어 있고, 특히 플라스틱 포장은 전세계 플라스틱 폐기물의 절반을 차지한다(Giacovelli, 2018). 이렇게 한 번 쓰고 버려
지는 플라스틱은 완전히 분해되는 대신 점점 더 작은 입자로 마모되거나 쪼개진다. 여기서 비교적 크기가 큰 플라스틱보 다 더 주목해야 하는 것은 바로 '미세플라스틱'이다. 미세플 라스틱(microplastics, MPs)이란 크기 0.001-5 mm의 합성수 지로서, 인위적으로 미세하게 제조된 1차 미세플라스틱과 크 기가 큰 플라스틱이 시간이 지나면서 풍화되어 작은 크기로 쪼 개진 2차 미세플라스틱으로 구분된다(Andrady, 2011; Wright 등, 2013)

\section{플라스틱은 생산과정 중 물리적, 화학적 성질을 극대화하}

*Corresponding author. E-mail : jisuns00@korea.kr, Phone : +82-32-440-5467, Fax : +82-32-440-5494

Received 03 November 2020; Revised 12 January 2021; Accepted 23 January 2021.

Copyright (c) The Korean Society of Food Preservation.

This is an Open Access article distributed under the terms of the Creative Commons Attribution Non-Commercial License (http://creativecommons.org/licenses/by-nc/4.0) which permits unrestricted non-commercial use, distribution, and reproduction in any medium, provided the original work is properly cited. 
기 위해 충전제, 난연제, 안정제, 가소제 등으로 사용되는 bisphenol-A, phthalates, tetrabromobisphenol A와 같은 화합 물이 첨가되는데, 이것은 플라스틱이 분해될 때 환경에 유출 되어 유해화학물질의 오염원으로 작용할 수 있다(Cole 등, 2011; Mato 등, 2001). 또한 미세플라스틱은 작게 분해된 공 극에 중금속을 포함한 무기물과 유기물 등의 오염물질이 흡 착되며, 특히 2-3 mm 크기의 플라스틱 펠릿은 잔류성유기오 염물질(persistent organic pollutants, $\mathrm{POPs}$ )에 대해 해수에 잔류하는 농도보다 약 $10^{5}$ 배 이상 높게 흡착하는 것으로 알 려져 있다(Mato 등, 2001; Piorek, 2004; Teuten 등, 2007). 더구나 미세플라스틱은 해양 오염뿐 아니라, 해양생물에 섭 식되어 플라스틱 자체의 물리적인 영향과 먹이사슬 내 독성 물질 이동의 전이 매개체로서 해양생태계에 영향을 미친다 (Engler, 2012). 이는 먹이사슬의 상위 포식자에게 유입되기 때문에 사람에게도 잠재적인 건강을 위협하는 요인이 될 가 능성이 있다.

미세플라스틱의 식별은 현미경(microscopy)을 사용하거나 육안으로 확인하는 물리적인 방법과 FT-IR 분광법(fourier transform infrared spectroscopy) 및 라만분광법(Raman spectroscopy)을 이용한 화학적 분석방법 그리고 Pyro-GCMS(pyrolysis gas chromatography mass spectrometry)를 이 용한 열분석(thermal analysis) 등 다양한 분석 방법으로 연구 되고 있으나, 물리적 방법만으로는 위양성 또는 위음성의 결 과가 초래될 수 있어 물리적 및 화학적인 방법의 조합으로 주로 연구된다(Shim 등, 2017b). 또한 생물학적 시료에서 미 세플라스틱을 추출하는 중요한 단계는 빠른 시간 내에 플라 스틱 폴리머 입자가 변형되거나 분해되지 않으면서 유기물을 효율적으로 제거하는 것이다. 이를 위해 $\mathrm{KOH}, \mathrm{NaOH}, \mathrm{H}_{2} \mathrm{O}_{2}$, $\mathrm{HNO}_{3}$ 등의 용매 사용, 가열, 비중분리 등을 통해 최적화된 조건을 찾는 연구가 병행되고 있다(Dehaut 등, 2016; Karami 등, 2017b). 현재 미세플라스틱 연구는 세계적으로 활발히 진 행 중이나 아직은 수산물이나 식염, 맥주, 꿀 등에 대한 연구 들만 일부 보고되고 있으며(Karami 등, 2017a; Liebezeit과 Liebezeit, 2013; Liebezeit과 Liebezeit, 2014; Shim 등, 2017a; Yang 등, 2015), 방법론이 제시되는 단계여서 다양한 유기물의 전처리 방법과 플라스틱 식별 방법으로 연구된 결 과의 비교는 한계가 있다. 또한 가공식품 중 미세플라스틱 연 구는 효율적인 식품별 매트릭스 제거 방법과 표준화된 기기 분석방법의 확립이 중요한 과제로 대두되고 있는 단계로 관 련 연구가 아직 미비한 실정이다.

본 연구에서는 인천 관내 유통 중인 수산물뿐 아니라, 수 산물가공품에서의 미세플라스틱의 잔류량과 플라스틱의 종 류 및 크기 등을 무작위로 평가하여 해양 유래 식품에서의 미세플라스틱 오염수준을 평가하고, 이를 통해 추후 광범위
한 미세플라스틱 오염도 측정 연구의 기초자료를 마련해 보 고자 하였다.

\section{재료 및 방법}

\section{시료 채집}

2019년 1-10월 중 인천 관내 유통 중인 수산물 51건, 수산 물가공품 50건을 재래시장, 마트 등에서 수거하여 미세플라 스틱 오염도 조사를 실시하였고, 이 중 수산물은 패류 20건, 어류 19건, 연체류 12건이고 수산물가공품은 통조림 19건, 젓 갈 11 건, 자숙수산물 8 건, 소스 8 건, 액젓 4 건이며, 수산물 중 살과 내장의 분리가 가능한 시료는 따로 채취하여 각각 검사 하였다.

\section{시료 전처리}

실험 진행 과정 중 시료가 오염될 가능성을 최소화하기 위 해 면소재의 실험복과 라텍스 장갑을 착용하였고, 모든 용액 은 사용하기 직전에 $20 \mu \mathrm{m}$ 정밀 표준망체(stainless-steel standard sieve; $20 \mu \mathrm{m} ; \phi 60 \times \mathrm{h} 18 \mathrm{~mm}$, CISA, Barcelona, Spain)에 여과하여 사용하였다. 또한 실험 용기는 다른 실험 에 사용되었던 용기와 혼용해서 사용하지 않고 단독으로 사 용하고, 가급적 유리나 스테인리스 소재를 사용하였으며, 모 든 용기는 사용 전에 $20 \mu \mathrm{m}$ 정밀 표준망체에 여과한 3차 증 류수로 세척하여 사용하였다.

시료의 전처리 방법은 보고된 연구를 참고하여 실험하였 다(Gundogdu, 2018; Karami 등, 2017b). 비커 1 L에 시료를 넣은 후 $15 \%$ 수산화칼륨 $(\mathrm{KOH}, J U N S E I, J a p a n)$ 용액과 $20 \%$ 과산화수소수 $\left(35 \% \quad \mathrm{H}_{2} \mathrm{O}_{2}\right.$, Daejung Chemicals and Metals, Co., Ltd., Siheung, Korea) 용액을 시료에 따라 볼륨 을 조정하여 $65^{\circ} \mathrm{C}$ 에서 $48-72$ 시간 교반하였다. 육안으로 유기 물 제거 정도를 확인한 후 mesh filter(stainless wire mesh; $45 \mu \mathrm{m} ; 47 \mathrm{~mm}$ diameter, Taemyong Science, Co., Ltd., Uiwang, Korea)로 감압 여과한 뒤, 데시케이터에서 자연 건 조하였다. 감압 여과한 mesh filter에 유기물이 남아있을 경우 위의 분해과정을 반복하여 진행하였다.

\section{$\mathrm{FT}-\mathrm{IR}$ 분석}

각각의 시료는 FT-IR(Nicolet iN10 MX Infrared Imaging Microscope, Thermo Fisher Scientific Inc., Waltham, MA, USA)을 이용하여 분석하였다. 건조된 mesh filter를 FT-IR 시료 분석구에 장착하고, Omnic Picta Program(Thermo Fisher Scientific Inc., Waltham, MA, USA)을 이용하여 filter의 전 면적을 최대 분석 가능한 면적으로 구획을 나눈 뒤 ultra-fast mapping을 통해 모든 면적의 IR spectrum을 획 
득하였다. 각각의 구획에서 얻어진 IR spectrum을 플라스틱 IR spectrum과 library matching을 통해 플라스틱의 재질을 판별하고, chemical image와 video image를 통해 그 크기를 측정하였다(Fig. 1).
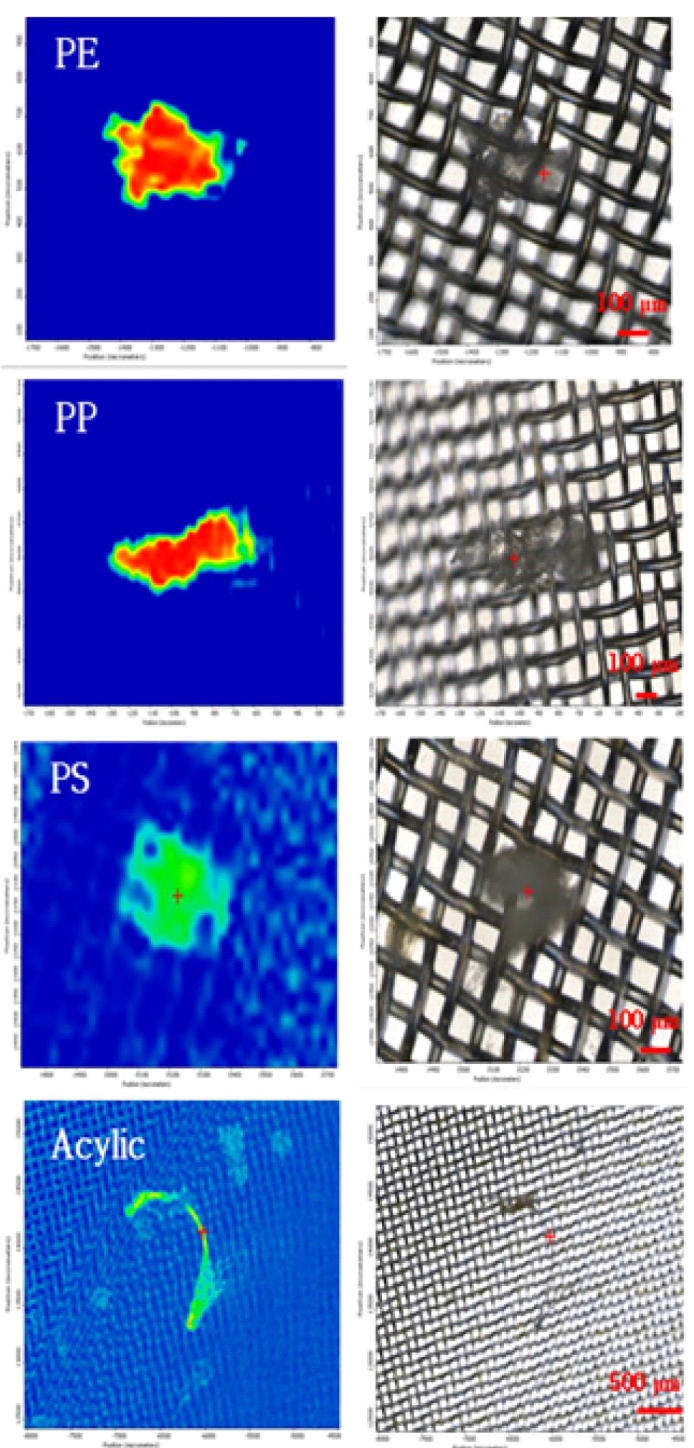

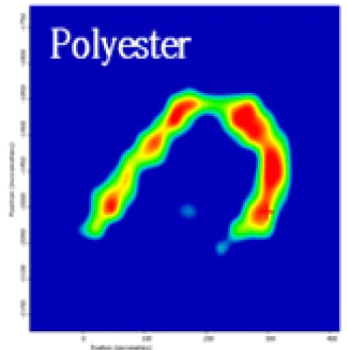

Chemical image

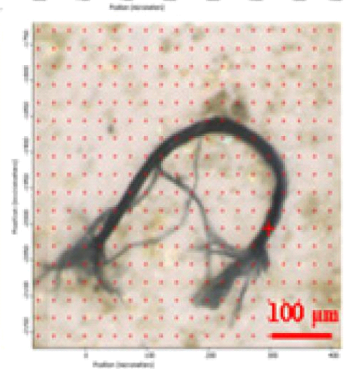

Video image
Fig. 1. FT-IR images of microplastics.

\section{결과 및 고찰}

\section{분석방법의 검증}

분석 과정에 대한 검증을 위해 시료와 동일한 분석방법을 적용하여 3개의 바탕시료(blank) 분석과 회수율(recovery, \%) 검사를 진행하였다. 바탕시료 당 총 미세플라스틱의 평균 입 자 수는 $0.67 \mathrm{MPs} / \mathrm{sample}$, 미세플라스틱재질 별 입자 수는 0.00-0.33 MPs/sample로 바탕시료 당 미세플라스틱의 오염 가능성이 $1 \mathrm{MPs} / \mathrm{sample}$ 이 넘지 않아 실제 시료에서 발견된 플라스틱은 유효한 값으로 처리하였으며, 잔류량은 바탕 값 을 빼지 않고 계산하였다(Table 1). 또한 $125-150 \mu \mathrm{m}$ 크기의 polyethylene pellet을 실험 재료와 동일한 분석방법을 적용하 여 회수율 검사를 3 회 실시하였으며, 평균 회수율 및 표준편 차(standard deviation, SD)는 $94.4 \pm 3.0 \%$ 로 신뢰할 만한 값임 을 확인하였다(Table 2).

\section{수산물 중 유형에 따른 미세플라스틱 잔류량}

모든 시료에서 미세플라스틱의 잔류량은 현재까지 보고된 국내·외 수산물 체내의 미세플라스틱 오염 관련 문헌 중 가 장 많이 사용되고 있는 시료 무게 당 $(\mathrm{g})$ 미세플라스틱의 잔류 량(microplastics, MPs), $\mathrm{MPs} / \mathrm{g}$ 으로 표기하였으며, 인천에서 유통되는 수산물의 전반적인 오염도를 파악하고자 다양한 종 류의 수산물에서 미세플라스틱 잔류량을 확인하였다. 수산물 총 51건(패류 20건, 어류 19건, 연체류 12건)의 자세한 유형별 검사건수와 각 시료 무게 당 $(\mathrm{g})$ 미세플라스틱 잔류량(MPs)으 로 나타낸 수치는 Table 3에 요약하였다. 수산물에서 어류와 연체류같이 살과 내장의 분리가 용이한 경우에는 따로 취하 여 각각 검사를 진행하였다. 개체 내 미세플라스틱의 오염은 해양에서 개체의 수동적 섭취 또는 입자를 먹이로 착각하여 섭취로 인한 오염일 가능성이 가장 크다고 판단되기 때문에 내장에 잔류하고 있는 양과 살에 잔류하는 양을 비교해봄으 로써 그 차이 또한 평가하고자 하였다. 그 결과, 어류 내장 $(4.07 \pm 8.91 \mathrm{MPs} / \mathrm{g})$ 에서 가장 많은 미세플라스틱 잔류량이 확 인되었고, 그 뒤로 가리비 $(1.61 \mathrm{MPs} / \mathrm{g})$, 낙지내장 $(1.33 \pm 1.78$ $\mathrm{MPs} / \mathrm{g}$ ) 순으로 나타났으며, 대체적으로 수산물 내장 > 수산 물 살 > 패류 순이었다. 그러나 각 시료의 미세플라스틱 잔류 량의 편차는 컸는데, 이는 개체의 차이뿐 아니라 수산물의 원 산지, 서식환경 및 출하 시기 등의 다양한 원인이 있을 것이 라고 추정된다. 국내 유통 중인 패류에서 미세플라스틱 잔류 량을 측정한 기존의 연구(Shim 등, 2017a)에서 보고된 결과 (담치: $0.12 \pm 0.10 \mathrm{MPs} / \mathrm{g}$, 굴: $0.07 \pm 0.06 \mathrm{MPs} / \mathrm{g}$, 바지락: $0.34 \pm 0.31 \mathrm{MPs} / \mathrm{g}$, 가리비: $0.08 \pm 0.08 \mathrm{MPs} / \mathrm{g}$ )와 본 연구 결과 를 비교해보면 상대적으로 높은 잔류량을 확인할 수 있었다. 그러나 국외 연구에서는 굴에서 최대 $12.18 \mathrm{MPs} / \mathrm{g}$, 담치에서 
Table 1. Mean of total MPs/sample and each type of MPs/sample in the blank sample

\begin{tabular}{cccccccc}
\hline & Total MPs & PE & PP & PS & Acrylic & PES & Others \\
\hline MPs/sample & $0.67 \pm 0.58^{1)}$ & 0.00 & $0.33 \pm 0.58$ & 0.00 & $0.33 \pm 0.58$ & 0.00 & 0.00 \\
\hline
\end{tabular}

${ }^{1)}$ Data are expressed as mean \pm SD $(n=3)$.

Table 2. Recovery rate of polyethylene particles

\begin{tabular}{cccccc}
\hline Material type & Size $(\mu \mathrm{m})$ & Density $(\mathrm{g} / \mathrm{mL})$ & Recovered number of particles per spiked number of particles & Recovery rate $(\%)$ \\
\hline Polyethylene & $125-150$ & 1.02 & $106 / 112$ & $107 / 110$ & $105 / 115$ \\
\hline
\end{tabular}

${ }^{1)}$ Data are expressed as mean $\pm \mathrm{SD}(\mathrm{n}=3)$.

Table 3. Abundance of residual MPs in seafoods

\begin{tabular}{|c|c|c|c|c|}
\hline Classification of type & No. of samples & Subclassification of types & No. of samples & $\mathrm{MPs} / \mathrm{g}$ \\
\hline \multirow{6}{*}{ Shellfish } & \multirow{6}{*}{20} & Mussel & 5 & $0.29 \pm 0.37^{1)}$ \\
\hline & & Oyster & 5 & $0.21 \pm 0.16$ \\
\hline & & Clam & 7 & $0.50 \pm 0.64$ \\
\hline & & Scallop & 1 & 1.61 \\
\hline & & Abalone (eviscerated flesh) & 1 & 0.82 \\
\hline & & Abalone (viscera) & 1 & 0.35 \\
\hline \multirow{2}{*}{ Fish } & \multirow{2}{*}{19} & Fish (eviscerated flesh) & 12 & $0.86 \pm 0.89$ \\
\hline & & Fish (viscera) & 7 & $4.07 \pm 8.91$ \\
\hline \multirow{4}{*}{ Mollusks } & \multirow{4}{*}{12} & Octopus (eviscerated flesh) & 3 & $0.20 \pm 0.18$ \\
\hline & & Octopus (viscera) & 3 & $1.33 \pm 1.78$ \\
\hline & & Squid (eviscerated flesh) & 3 & $0.42 \pm 0.40$ \\
\hline & & Squid (viscera) & 3 & $0.26 \pm 0.14$ \\
\hline
\end{tabular}

${ }^{1)}$ Data are expressed as mean \pm SD.

13.65 MPs/g의 연구도 있었으며(Leslie 등, 2017), 대체적으로 는 본 연구와 비슷한 수준의 결과를 보였다(Davison과 Dudas, 2016; Van Cauwenberghe과 Janssen, 2014; Vandermeersch 등, 2015). 이러한 결과는 인천 지역의 수산물 및 수산물가공 품의 미세플라스틱 오염도가 국내 타 연구 결과에 비해 상대 적으로 높다고 판단될 수 있으나, 기존 연구 결과와의 비교는 검사 방법의 차이로 인해 한계가 존재하며, 보다 광범위하고 지속적인 연구가 필요할 것이라 사료된다.

\section{수산물 중 미세플라스틱 재질별 잔류량}

수산물에서 검출된 미세플라스틱 종류로는 polyethylene (PE), polypropylene(PP), acrylic, polystyrene(PS), polyester (PES), nylon, polyurethane(PU), polyvinyl chloride(PVC), polyethylene terephthalate(PET), epoxy resin 등이 있었다. 전체 검출된 미세플라스틱 재질별 비율(\%)의 크기는 $\mathrm{PE}$ $(34.1 \%)>\operatorname{PP}(32.4 \%)>\operatorname{PS}(12.5 \%)>\operatorname{PES}(10.2 \%)>$ acrylic (8.1\%) 순이며, 각 유형별 재질별 비율 모두 $\mathrm{PE}$ 와 PP가 가장 우세한 조성으로 확인되었다(Fig. 2). 패류 중 PS의 검출 조 성이 가리비 $(0 \%)$ 와 바지락 $(0.3 \%)$ 에서와는 다르게 굴( $22.9 \%)$ 과 담치 $(2.7 \%)$ 에서는 높게 나타났는데, 이는 서식환경과 관계 가 있는 것으로 판단된다. 굴과 담치는 발포스티렌(expanded polystyrene, EPS) 부자에 연결된 줄에 부착시켜 키우는 연승 수하식 방법으로, 수심 $8 \mathrm{~m}$ 이내의 수층에서 양식되어 밀도 가 낮은 폴리머인 $\operatorname{EPS}\left(0.15 \mathrm{~g} / \mathrm{cm}^{3}\right)$ 가 바지락과 가리비에 비 해 굴과 담치 체내에 많이 축적되었을 것으로 보고된 바 있다 (NIFS, 2012; Shim 등, 2017a). 


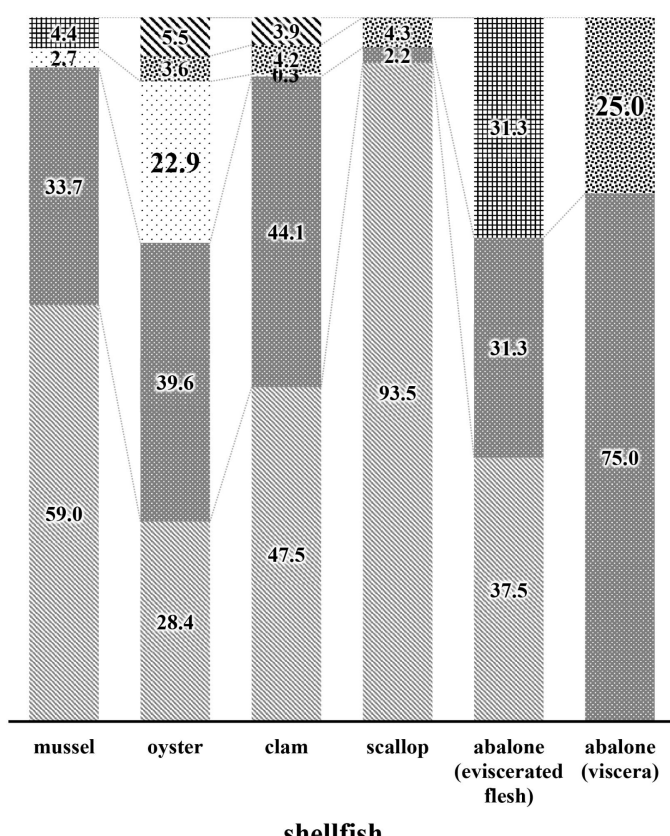

shellfish

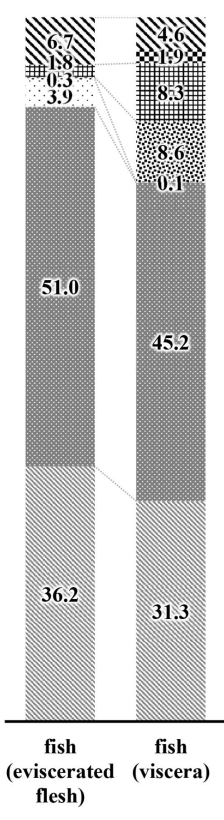

fish

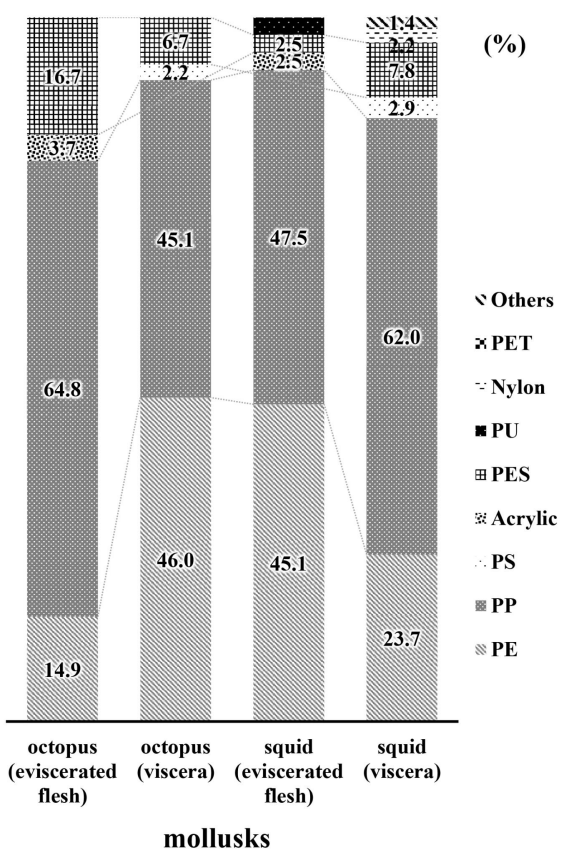

Fig. 2. Microplastic composition in seafoods.

\section{수산물 중 미세플라스틱 크기별 잔류량}

수산물의 체내에서 다양한 크기의 미세플라스틱이 검출되 었는데, 검출된 미세플라스틱 크기를 측정하여 5 개의 범위로 구간을 나누어 분포를 확인하였다(Table 4). 재료의 전처리
시 유기물 제거 후 최종 $45 \mu \mathrm{m}$ mesh filter에 여과하였기 때 문에 cut-off size는 $45 \mu \mathrm{m}$ 다. 미세플라스틱의 크기는 길이 (length)와 폭(width)을 측정하였는데 크기 범위를 판단할 때 두 개의 값 중 측정한 크기가 큰 값이 범위에 선택되도록 하

Table 4. Distribution \% of different microplastic sizes in seafoods

\begin{tabular}{|c|c|c|c|c|c|}
\hline \multirow{2}{*}{ Subclassification of types } & \multicolumn{5}{|c|}{ Size $(\mu \mathrm{m})$} \\
\hline & $45-100$ & $100-200$ & $200-500$ & $500-1,000$ & $1,000-5,000$ \\
\hline Mussel & $33.5 \pm 39.1^{1)}$ & $48.2 \pm 37.7$ & $9.5 \pm 15.8$ & $7.5 \pm 10.5$ & $1.2 \pm 2.7$ \\
\hline Oyster & $17.8 \pm 29.0$ & $36.9 \pm 24.1$ & $33.3 \pm 20.4$ & $2.0 \pm 4.5$ & $10.0 \pm 22.3$ \\
\hline Clam & $23.0 \pm 22.0$ & $44.6 \pm 22.3$ & $28.2 \pm 22.0$ & $2.9 \pm 4.3$ & $1.3 \pm 3.4$ \\
\hline Scallop & 76.1 & 19.6 & 2.2 & 2.2 & 0.0 \\
\hline Abalone (eviscerated flesh) & 0.0 & 12.5 & 37.5 & 12.5 & 37.5 \\
\hline Abalone (viscera) & 12.5 & 12.5 & 37.5 & 25.0 & 12.5 \\
\hline Fish (eviscerated flesh) & $9.6 \pm 8.2$ & $31.5 \pm 20.4$ & $36.2 \pm 21.7$ & $9.3 \pm 15.3$ & $5.0 \pm 8.9$ \\
\hline Fish (viscera) & $13.5 \pm 10.2$ & $25.6 \pm 20.3$ & $30.5 \pm 20.5$ & $12.5 \pm 15.0$ & $3.6 \pm 6.2$ \\
\hline Octopus (eviscerated flesh) & $7.4 \pm 12.8$ & $38.9 \pm 9.6$ & $46.3 \pm 22.5$ & $7.4 \pm 12.8$ & $0.0 \pm 0.0$ \\
\hline Octopus (viscera) & $16.0 \pm 22.2$ & $41.1 \pm 8.4$ & $35.3 \pm 17.5$ & $5.3 \pm 7.1$ & $2.2 \pm 3.8$ \\
\hline Squid (eviscerated flesh) & $15.7 \pm 8.0$ & $36.7 \pm 16.4$ & $41.3 \pm 8.4$ & $2.5 \pm 4.3$ & $3.7 \pm 6.4$ \\
\hline Squid (viscera) & $29.9 \pm 18.7$ & $42.5 \pm 15.9$ & $18.8 \pm 7.1$ & $5.1 \pm 4.5$ & $3.7 \pm 3.4$ \\
\hline
\end{tabular}

\footnotetext{
${ }^{1)}$ Data are expressed as mean \pm SD
} 
였다.

전체적으로 100-500 $\mu \mathrm{m}$ 범위의 크기가 우세하였다. 그러 나 수산물의 개체 크기가 작은 홍합, 굴, 바지락의 경우 200 $\mu \mathrm{m}$ 이하의 범위의 크기가 가장 우세하였으나, 개체 크기가 큰 어류나 연체류의 경우엔 100-500 $\mu \mathrm{m}$ 범위의 크기가 가장 우세했다. 패류의 주요 크기 조성은 패류에서 미세 플라스틱 잔류량을 측정한 기존의 국내 연구(Shim 등, 2017a)와 유사 한 결과를 보여주었으며, $500 \mu \mathrm{m}$ 이상의 크기는 대체로 fiber 형태의 PES였다.

\section{수산물가공품 중 유형에 따른 미세플라스틱 잔류량}

수산물가공품의 미세플라스틱 잔류량 표기(MPs/g) 등의 조건은 수산물 검사와 동일하다. 수산물가공품 총 50건은 통 조림, 젓갈, 자숙수산물, 소스, 액젓이며, 자세한 유형별 검사 건수와 각 시료 무게 당 $(\mathrm{g})$ 미세플라스틱 잔류량( $\mathrm{MPs})$ 으로 나타낸 수치는 Table 5에 요약하였다.

젓갈 $(1.73 \pm 1.73 \mathrm{MPs} / \mathrm{g})$ 에서 가장 많은 미세플라스틱이 검 출되었으며, 그 뒤로 통조림 > 자숙수산물 > 소스 > 액젓 순 으로 확인되었다. 또한, 수산물 자체의 함유량이 대부분인 가 공품(자숙수산물, 통조림, 젓갈)이 함유량이 낮은 가공품(소 스, 액젓)에 비해 미세플라스틱 잔류량이 높게 검출되었다. 또한 젓갈 11 건 중 창난젓 4 건의 평균 미세플라스틱 잔류량 은 3.12 $\pm 2.35 \mathrm{MPs} / \mathrm{g}$ 으로 수산물가공품 중 가장 높은 오염도 를 나타냈는데, 이는 창난젓은 명태의 창자만을 소금에 절여 만든 것으로 수산물 내장에서 미세플라스틱 잔류량이 가장 높게 검출된 결과와 연관이 있는 것으로 판단된다. 이러한 결 과는 미세플라스틱 잔류량이 수산물 원료에서 유래될 가능성 이 가공 공정에서 유입되는 가능성보다 높다고 사료된다.

\section{수산물가공품 중 미세플라스틱 재질별 잔류량}

수산물가공품에서 검출된 미세플라스틱 종류는 수산물과 같았다. 전체 검출된 미세플라스틱 재질별 비율(\%)은 $\mathrm{PE}$ $(47.8 \%)>\operatorname{PP}(33.2 \%)>\operatorname{acylic}(12.5 \%)>\operatorname{PES}(2.9 \%)>$ $\mathrm{PS}(1.9 \%)$ 순이었다. 각 유형별 재질별 비율 모두 PE와 PP가
가장 우세한 조성으로 확인되었으며, 이는 수산물의 결과와 유사했다(Fig. 3).

\section{수산물가공품 중 미세플라스틱 크기별 잔류량}

수산물가공품 중 검출된 미세플라스틱의 크기 측정 및 범 위구간, cut-off size는 수산물 검사와 같다(Table 6). 수산물 가공품 전체에서는 수산물과 마찬가지로 100-500 $\mu \mathrm{m}$ 범위 의 크기가 우세하였다. 하지만 수산물과 달리 수산물가공품 은 분류한 대상에 포함된 개체의 유형 및 수산물 함량 등의 차이가 다양했기 때문에 검출된 미세플라스틱 크기와 개체 크기와의 연계성은 파악하지 않았다. 그러나 홍합살, 조갯살

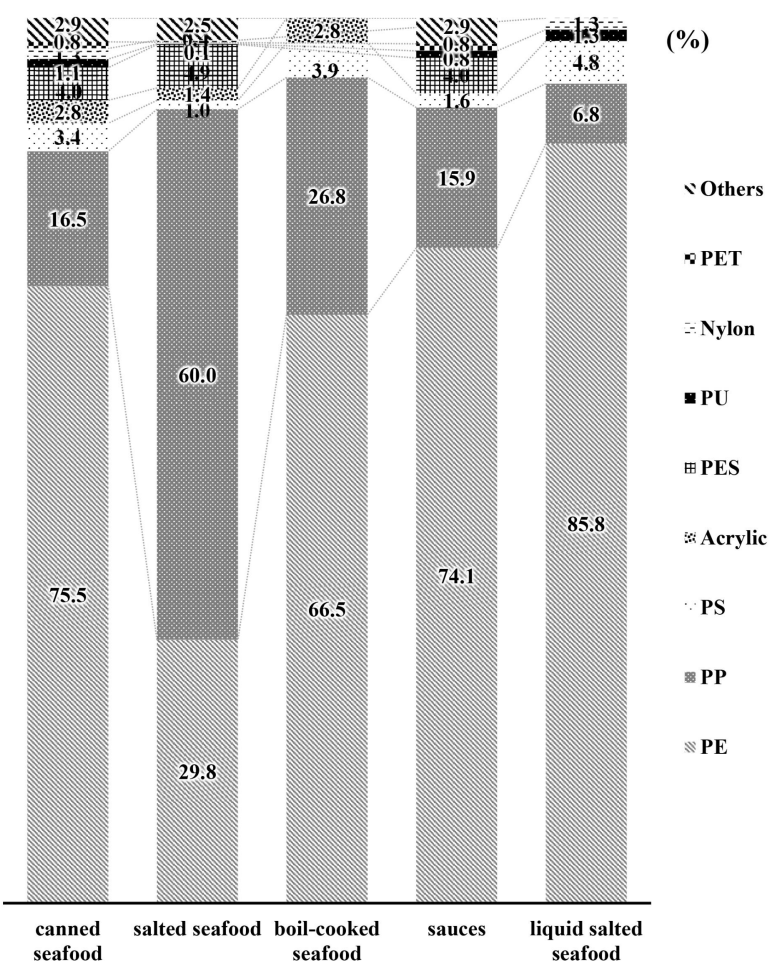

Fig. 3. Microplastics composition in processed seafood products.

Table 5. Abundance of residual microplastics in processed seafood products

\begin{tabular}{ccccc}
\hline Classification of types & No. of samples & Subclassification of types & MPs/g \\
\hline Canned seafood & 19 & Canned tuna, canned cockle, canned seasnail & $0.48 \pm 0.45^{1)}$ \\
Salted seafood & 11 & Salted shrimp, sauced clam, sauced intestine & $1.73 \pm 1.73$ \\
Boil-cooked seafood & 8 & Messel flesh, shrimp meat, clam meat & $0.47 \pm 0.36$ \\
Sauces & 8 & Oyster sauce, tuna source & $0.32 \pm 0.21$ \\
Liquid salted seafood & 4 & Anchovy sauce, sand lance extract & $0.26 \pm 0.19$ \\
\hline
\end{tabular}

\footnotetext{
${ }^{1)}$ Data are expressed as mean $\pm \mathrm{SD}$.
} 
Table 6. Distribution \% of different microplastics sizes in processed seafood products

\begin{tabular}{cccccc}
\hline \multirow{2}{*}{ Subclassification of types } & \multicolumn{4}{c}{ Size $(\mu \mathrm{m})$} \\
\cline { 2 - 6 } & $45-100$ & $100-200$ & $200-500$ & $500-1,000$ & $1,000-5,000$ \\
\hline Canned seafood & $5.5 \pm 6.6^{1)}$ & $39.5 \pm 20.1$ & $31.4 \pm 16.5$ & $14.2 \pm 21.7$ & $4.1 \pm 6.4$ \\
Salted seafood & $14.7 \pm 9.1$ & $32.3 \pm 10.1$ & $31.7 \pm 12.0$ & $13.8 \pm 5.7$ & $8.4 \pm 0.2$ \\
Boil-cooked seafood & $39.3 \pm 19.6$ & $30.1 \pm 16.7$ & $20.4 \pm 20.7$ & $3.9 \pm 5.9$ & $0.6 \pm 1.6$ \\
Sauces & $10.1 \pm 6.7$ & $44.0 \pm 24.3$ & $39.5 \pm 29.2$ & 3.1 & $5.0 \pm 10.0$ \\
Liquid salted seafood & $28.4 \pm 4.9$ & $32.3 \pm 27.1$ & $34.3 \pm 22.6$ & $0.0 \pm 0.0$ \\
\hline
\end{tabular}

${ }^{1)}$ Data are expressed as mean \pm SD.

등 자숙수산물의 경우에는 $200 \mu \mathrm{m}$ 이하 범위의 크기가 가장 우세하였으며, 이는 수산물의 패류 결과와 같았다. 자숙수산 물이 $100 \%$ 수산물이며, 그 대부분이 패류임을 감안하였을 때 예상되는 결과라 할 수 있다.

\section{요 약}

본 연구에서는 인천 관내 유통 중인 수산물 및 수산물가공 품에 대한 미세플라스틱 잔류실태를 조사하여 식품 중 미세 플라스틱 안전방안에 대한 기초자료를 마련하고자 하였다. 인천 관내 수산물 51 건과 수산물가공품 50 건의 미세플라스 틱 잔류량 $(\mathrm{MPs} / \mathrm{g})$ 과 재질성분 및 크기 분포를 분석하였을 때 평균 미세플라스틱 잔류량은 수산물에서 $1.06 \pm 3.38 \mathrm{MPs} / \mathrm{g}$, 수산물가공품에서 $0.89 \pm 1.29 \mathrm{MPs} / \mathrm{g}$ 으로 확인되었다. 또한 수산물과 수산물가공품 모두 100-500 $\mu \mathrm{m}$ 범위의 크기의 PE 와 $\mathrm{PP}$ 의 조성이 가장 높게 나타났다. 수산물 내장과 수산물 의 내장을 원료로 한 젓갈에서 높은 미세플라스틱 잔류량이 확인되었으며, 시료 개체의 크기가 작은 패류 및 자숙수산물 은 $200 \mu \mathrm{m}$ 이하 범위의 크기가 우세하였고, 개체 크기가 큰 어류나 연체류의 경우엔 100-500 $\mu \mathrm{m}$ 범위의 크기가 가장 우 세했다. 따라서 개체의 크기에 따라 검출된 플라스틱의 주요 크기도 영향이 있음을 확인하였다. 모든 시료에서 미세플라 스틱의 오염 수준은 같은 유형에서도 각 시료마다 차이가 컸 는데, 수산물 개체 또는 수산물가공품의 재료의 차이도 물론 존재하지만, 보다 명확한 분석을 위해서는 서식 환경, 출하 시기, 원산지, 생산공정 등의 정보파악이 필요하며, 광범위 하고 지속적인 데이터 축적을 통해 미세플라스틱 오염도 분 석의 신뢰성을 향상시킬 수 있을 것이라 판단된다. 무엇보다 도, 기존의 연구 결과와의 비교는 분석법의 다양성으로 인해 직접비교에는 한계가 있어, 미세플라스틱의 표준화된 분석 방법의 필요성이 절실히 요구된다.

\section{Conflict of interests}

The authors declare no potential conflict of interest.

\section{ORCID}

Ji Sun Kim https://orcid.org/0000-0002-2835-4121

\section{References}

Andrady AL. Microplastics in the marine environment. Mar Pollut Bull, 62, 1596-1605 (2011)

Birol F. The future of petrochemicals: Towards more sustainable plastics and fertilizers. International Energy Agency, Paris, France, p 15-26 (2018)

Cole M, Lindeque P, Halsband C, Galloway TS. Microplastics as contaminants in the marine environment: A review. Mar Pollut Bull, 62, 2588-2597 (2011)

Davidson K, Dudas SE. Microplastic ingestion by wild and cultured Manila clams (Venerupis philippinarum) from Baynes Sound, British Columbia. Arch Environ Contam Toxicol, 71, 147-156 (2016)

Dehaut A, Cassone AL, Frere L, Hermabessiere L, Himber C, Rinnert E, Riviere G, Lambert C, Soudant P, Huvet A, Duflos G, Paul-Pont I. Microplastics in seafood: Benchmark protocol for their extraction and characterization. Environ Pollut, 215, 223-233 (2016)

Engler RE. The complex interaction between marine debris and toxic chemicals in the ocean. Environ Sci Technol, 46, 12302-12315 (2012)

Giacovelli C. Single-Use Plastics: A Roadmap for Sustainability. United Nations Environment Programme, Nairobi, 
Kenya, p 6-16 (2018)

Gundogdu S. Contamination of table salts from Turkey with microplastics. Food Addit Contam Part A, 35, 10061014 (2018)

Karami A, Golieskardi A, Ho YB, Larat V, Salamatinia B. Microplastics in eviscerated flesh and excised organs of dried fish. Sci Rep, 7, 5473 (2017a)

Karami A, Golieskardi A, Choo CK, Romano N, Ho YB, Salamatinia B. A high-performance protocol for extraction of microplastics in fish. Sci Total Environ, 578, 485-494 (2017b)

Leslie HA, Brandsma SH, van Velzen, MJM, Vethaak AD. Microplastics en route: Field measurements in the Dutch river delta and Amsterdam canals, wastewater treatment plants, North Sea sediments and biota. Environ Int, 101, 133-142 (2017)

Liebezeit G, Liebezeit E. Synthetic particles as contaminants in German beers. Food Addit Contam Part A, 31, 1574-1578 (2014)

Liebezeit G, Liebezeit E. Non-pollen particulates in honey and sugar. Food Addit Contam Part A, 30, 2136-2140 (2013)

Mato $\mathrm{Y}$, Isobe $\mathrm{T}$, Takada $\mathrm{H}$, Kanehiro $\mathrm{H}$, Ohtake $\mathrm{C}$, Kaminuma T. Plastic resin pellets as a transport medium for toxic chemicals in the marine environment. Environ Sci Technol, 35, 318-324 (2001)

NIFS. Standard Manual of Pacific Oyster Hanging Culture. National Institute of Fisheries Science, Busan, Korea, $p$ 23-25 (2012)
Piorek S. Feasibility of analysis screening of plastics for heavy metals with portable X-ray fluorescence analyzer with miniture X-ray tube. Global Plastics Environmental Conference, 18-19 February, Detroit, MI, USA, Abstract \#14 (2004)

Shim WJ, Hong SH, Cho YN, Han GM, Song YK, Jang M, Eo S, Hong L, Andrew LJY. Research on Food Safety Management for Microplastics. Korea Institute of Ocean Science and Technology, Busan, Korea, p 1-99 (2017a) Shim WJ, Hong SH, Eo SE. Identification methods in microplastic analysis: A review. Anal Methods, 9, 13841391 (2017b)

Teuten EL, Rowland SJ, Galloway TS, Thompson RC. Potential for plastics to transport hydrophobic contaminants. Environ Sci Technol, 41, 7759-7764 (2007)

Vandermeersch G, Van Cauwenberghe L, Janssen CR, Marques A, Granby K, Fait G, Kotterman MJJ, Diogene J, Bekaert K, Robbens J, Devriese L. A critical view on microplastic quantification in aquatic organisms. Environ Res, 143, 46-55 (2015)

Van Cauwenberghe L, Janssen CR. Microplastics in bivalves cultured for human consumption. Environ Pollut, 193, 65-70 (2014)

Wright SL, Thompson RC, Galloway TS. The physical impacts of microplastics on marine organisms: A review. Environ Pollut, 178, 483-492 (2013)

Yang D, Shi H, Li L, Li J, Jabeen K, Kolandhasamy P. Microplastic pollution in table salts from China. Environ Sci Technol, 49, 13622-13627 (2015) 